\title{
Planned Solutions in Tourism in Terms of COVID-19
}

\author{
Head Assist. Prof., PhD Nadezhda Veselinova \\ D. A. Tsenov Academy of Economics - Svishtov, Svishtov, Bulgaria \\ n.veselinova@uni-svishtov.bg
}

\begin{abstract}
The special situation in which the tourism industry finds itself requires the search for new paradigms for dealing with the emerging reality. This paper examines different approaches to planning activities in the tourism sector in an unprecedented pandemic environment. It is proposed to systematically solve the emerging problems through targeted-adaptive attitude to the environment. Attention is paid to the possibility for flexibility of the decisions in order to achieve optimality of the results, the possibilities for alternative in the choice of strategic and tactical solutions for dealing with problems are presented.
\end{abstract}

Keywords: planning, flexible planning, planning decisions, situational planning

JEL Code: L83, M21, O21, P41 DOI: https://doi.org/10.36997/IJUSV-ESS/2020.9.3.80

Responsible managers in the field of tourism, especially in the current conditions of unprecedented crisis, must make judgments about exactly what planned activities to use and what planning decisions to make to achieve the goals set for the business organization. The functions they perform and the relations in which the planned activities enter have the greatest influence in the formation of a system for their management, including in making managerial decisions. Therefore, when considering a particular system of planning activities, it is necessary to clarify what type it is, what is characteristic and how it affects the functioning and development of planning activities in order to navigate the complex tangle of their action and direction., which is especially important in planning decisions and their information provision so that they are effective and useful to the organization.

The characteristic complex connections and various activities in the tourist companies objectively lead to an increase in the requirements for special positions in the management of the planned activities. This suggests that in the most general form, the process related to the construction of the planning system in the planning functions of companies in the field of tourism could be characterized by the following main aspects related to conceptualization, creation and implementation (see Figure 1 ).

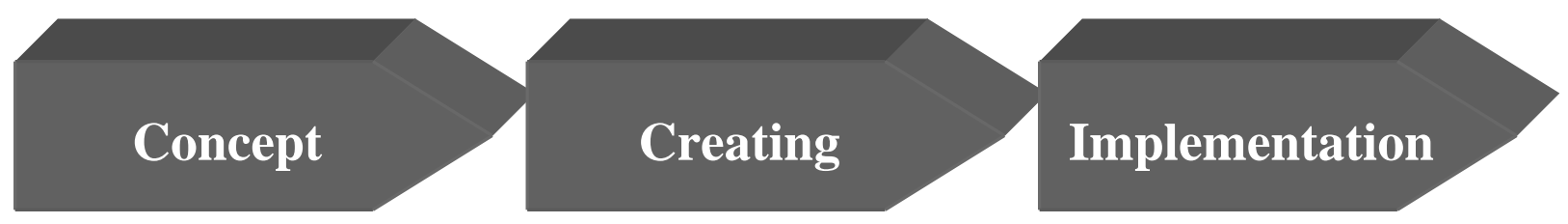

Figure 1. Process of building a planning system

If we take as a starting point Weber's view that integration between different views is necessary in order to use different concepts to differentiate a system, then it is necessary to make decisions about their balanced use. Because the conceptual examination of the planning system presupposes the examination of its functional differentiation, institutional design and instrumental armament in the context of the set goals, the concepts related to the functional differentiation and institutional presentation of the planning systems have gained greater application (Gotthard, 2001). 
Appropriate in the current crisis in tourism is the use of a concept based on coordination, it is based on the differences between the management system and the implementation system. A special case of this concept is the construction of a concept based on planning. P. Horvat discusses the coordination of the subsystems planning, control and information provision, presents the system-forming and system-binding coordination. By system-forming coordination is meant the creation of systems and structures that help to coordinate tasks. System-binding coordination means the coordination of the activities carried out within a given system structure for solving a problem, as well as the storage and adaptation of the information link between the subsystems.

It is the concept based on planning, due to the opportunities it offers and the specifics of the studied object would be most appropriate to use as a foundation for construction.

Therefore, the conceptual perspective imposes the view that the planning system provides a choice of solutions and activities in subsystems, determines the relationships between them and the latter are arranged in time and space. The existence of each separate activity or subsystem is part of the planning system, in this regard the proposed system uses part of the internal resources of the planning system, has certain rights, is responsible for certain results (in kind, information and value).

In order to survive in modern realities, it is necessary for companies in the field of tourism to be formed as flexible and proactive. In this regard, the planned activities should be organized as artificial, economic, behavioral systems. Like any system, the system of planned activities should have a specific goal to achieve. In order to achieve this, it is necessary to have certain means resources, with the help of which to achieve the set goal. This creates the first relationship between purpose and resources. It should be borne in mind here that in the systems that make up the planned activities, the resources can be divided into two main groups:

$>\quad$ main resources from the point of view of the planning system, which are defined as follows:

- plan managers;

- planning specialists - a decisive role belongs to the planning specialists, as they influence the implementation of the planning activities and especially the relations between the separate elements in the system. In addition, the various interests that cannot but be taken into account in the management of the system also have an impact;

- $\quad$ planned information / planned information system;

- funds providing the planning management (ie helping to implement the planning decisions in the planning activities);

- $\quad$ providing planning;

the integration resources of the marketing management provide the necessary organization in the realization of the marketing activity and help for that:

- $\quad$ planning documents;

- the means by which the organization of the planned activities is achieved, both in the current ones (the organization of planned activities in statics) and in the future periods (the organization of the planned activities in dynamics).

To achieve the planned goals, it is not enough to have only resources to carry out the planned activities, but the components of these resources must be in a certain relationship with each other. Therefore, the planned activities need to be organized in a system. On this basis, these relations are further developed.

What is special about this system is that each group of activities must find its place. Indeed, the main resources are those that dominate and determine the nature of the system of planning 
activities. However, integration resources should not be neglected either, because without them it is not possible to achieve the goal effectively.

The system of planned activities has its own scale and specific set of inputs - places where the system is affected, and outputs, which affect the results of the operation and development of the system.

We could point out that the planned activities as a system are characterized by the fact that the set goal largely determines the means and methods that will be used, having the character of open systems. He can also argue that there is a need for ultra-resilience to planning systems and a need for their flexibility.

The set goal largely determines the means and methods that will be used, as well as the direction of all planning activities. This is expressed in the purposeful behavior of the complex of planned activities towards the realization of pre-determined and agreed goals. The reason for the formation of a planning system can also be sought there, because the striving to achieve the global goal set for the company makes necessary the impact achieved as a result of the planned activities. In order to have a result, the purpose of the system of planned activities must be in accordance with the objective laws of development, the goals of larger systems, the capabilities of the system itself, the efficient use of resources, ie. mobilization of all inputs for the system of planned activities and to use them to serve the purpose they face. The influence of the environment and its possibilities is also extremely important.

The existence of the planned activities is related to the implementation of a number of conditions and relationships with the environment. The analysis and assessment of the state and development trends of a given business unit turn out to be in practice an easier task, compared to the complex analysis of the dynamically changing external environment for obvious reasons: the lower level of awareness; the lack of opportunity for effective control; the dynamic nature of the changes; the huge variety of reactions, etc., which make it especially difficult to study and evaluate the favorable and negative impacts of the environment on the company. The purpose of this analysis is to reveal how our environment will react to the characteristics of our own company, and vice versa - what strategy, policy and tactics we will adopt to achieve the goals and sub-goals. In order to achieve the best results from the research and assessment of the nature and strength of the influence of the external environment on the organization in the situation created as a result of COVID, it is necessary to distribute the influencing factors in certain groups at macro, meso and micro level. A sharp boundary between these groups of factors of the external environment, from the standpoint of the hierarchical level in economic life, would not be correct to draw. The macroenvironment is represented by the forces, on a broader social level, which forces influence the microenvironment. The group of macro-factors includes: social, economic, technological, legal-political, cultural, as well as those of business ethics and morality. The influence of these factors shows a number of specific characteristics that determine the nature, strength and mode of impact on the life of the modern company. This influence is above all uncontrollable by the companies participating in the economic life. In practice, this means that changes in the business environment follow their own course under the influence of a complex system of macrofactors. However, it would be wrong to absolutize this statement, because each company could react differently to the impact of the business environment.

The meso level is characterized primarily by competitive factors, the influence of the market, the industry to which the company belongs, and others. The meso-environment is formed by the branch, regional and institutional environment. When studying and assessing the industry environment, attention should be drawn to: 
- assessment of the stage of economic development in which the industry is developing crisis, depression, recovery, recovery;

- derivation of main characteristics of the industry;

- analysis of the concentration in the industry.

Microfactors are directly related to the impact that the company's intercompany relations with its suppliers, customers, intermediaries, competitors and contact audience have. The microenvironment is represented by the forces directly related to the company itself. It includes the stakeholder group (so-called target environment) with which the business system works. The microenvironment encompasses the elements with which the company is in direct contact. Here the influence on marketing activity is direct. For its part, the company can also influence these elements and direct them to its needs.

The modern world economy is rightly called the digital economy. The global and highly standardized communication infrastructure has led to the micronization of the efforts of the individual participant in the tourism sector to a fully possible and competitive activity. The growth of the geographical scope of the business activity of the companies is accompanied by a number of advantages, the digital economy: the connection with the client becomes very effective and in real time; the electronic information connection bidder-consumer determines an increase in the competitiveness of the bidders; enrichment and increase of the efficiency of the used marketing tools; improving such essential aspects of the company's activity as the organization and management, the logistic activity, the selection and qualification of the personnel, etc.

The digital economy offers advantages to the users themselves: access to very rich information; access to much greater diversity; reducing the time for contacts with preferred companies; increase the strength of the buyer in comparison with the offeror.

Economic factors prove to be decisive for the companies impacts related to income, respectively the solvency of potential and real customers, the living standard of the selected target market groups, the propensity and opportunity for savings, the availability of loans, changes in the positions of the company in the tourism structure. of national economies. Overcoming these problems, typical for the Bulgarian economy, is a long process, including efficient use of local resources, attracting investments, expanding markets. At the same time, it is especially important to look for new business models for knowledge transfer and implementation of innovative technologies, ensuring high productivity and directing production to products with high added value (Kabakchieva, 2019). And the Planner is obliged to monitor in detail, analyze, forecast and plan the connections and dependencies between the complex of planning activities and decisions and the development of the main phases in the course of the business cycle - rise, recession, recovery. A wide range of indicators is used for a systematic study of: the absorption capacity and degree of elasticity of national or regional markets; the nature and development trends of economic systems; consumption structures; dependence on participation in international economic relations and other factors of international relations. The differences in the economic development of the separate national and regional markets are especially significant.

The existence of the planned activities is related to the implementation of a number of conditions and relationships with the environment. These conditions and relationships are bilaterally subject to a number of requirements, the normal implementation of which depends on their course. The lack of the above conditions introduces additional disturbances in the planning system (see Figure 2), which may divert it from the planned development to such an extent that the conditions for operational regulation and reduction of the impact of deviations are too difficult and get unfavorable results. 


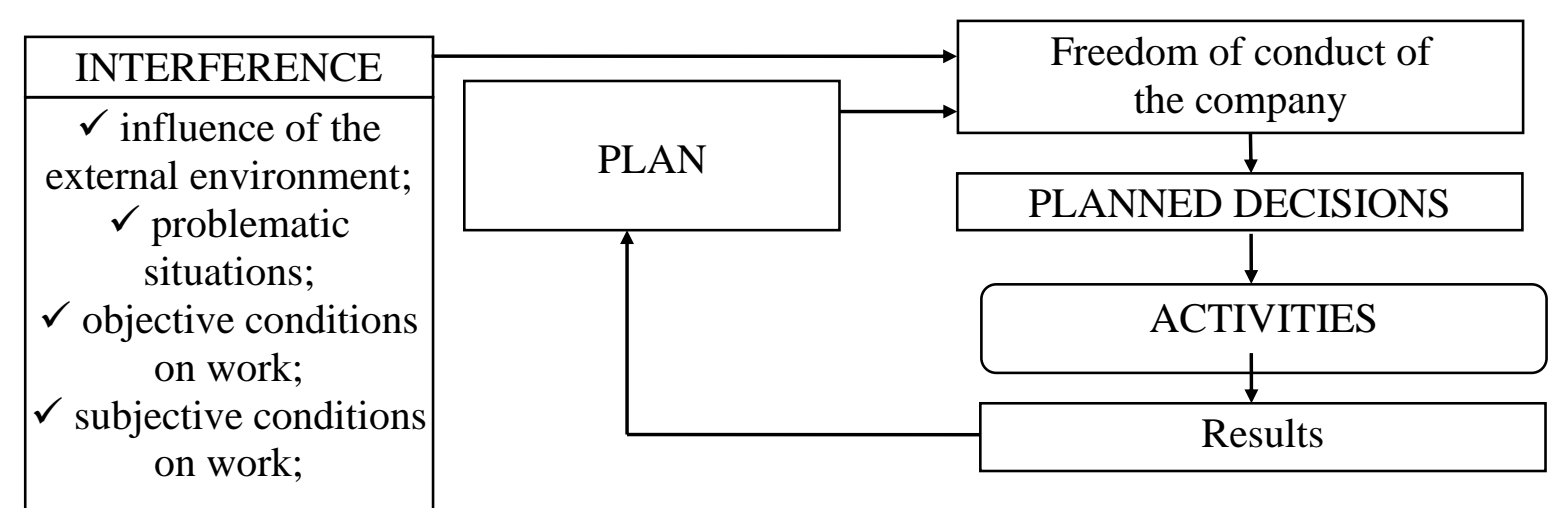

Figure 2. Influence of disturbances on the behavior of the planning system

On the other hand, due to the occurring disturbances in its internal state, the planning system influences these relations, introducing a number of fluctuations in them.

This means that the proper management of the planning system requires to reduce the impact of interference and to develop these relationships in the most favorable way according to the requirements that are set for its successful operation. (Slavova, I., 2009)

Therefore, planning, due to the dynamics of the environment, flexible scenario planning, in such an economic situation becomes a key concept for any activity. The great importance of future perspectives in business planning requires that plans and strategies be recognized as contributing to the efforts of general planning on a broad basis, while being guided by general planning.

A concept is needed that is based on planning, providing priority, opportunities for variability and flexibility in the implementation of planning decisions and activities. In response to the challenges of the environment, it is necessary to plan which includes those decisions and activities that lead to a predetermined series of planned actions (Figure 3). On the one hand, the planning system performs activities related to the planned function of control, related to solving problem situations, including those that it carries out within the framework of its chosen behavior. Strategic choices are needed, which come down to integrating the mission, goals, opportunities and threats, as well as taking into account internal resources as well as the challenges of the environment. (Dimitrov N. Zafirova Tsv., 2001)

The presented system uses planning to make choices about the variety of activities, among a set of target states, a set of actions and a sequence of their implementation. This set will constitute possible behaviors. Among them stand out a group of possible behaviors that the planning system perceives as preferred. Only one of them is chosen, the so-called selected behavior. (Stoyanov V. and others, 1987)

In this light, the field of preferred variants represents an area of increased probability of performing a certain behavior, i. the set of activities performed by the planning system. Through planning, the transition from the zone of possible variants of behavior to the zone of preferred variants is carried out with the help of a system of criteria for assessing the actual situation. The transition from the preferred behaviors to the specifically chosen option is based on the prioritization of these criteria based on the interests and needs of the company. The expected result is the ability of the system for such actions, which are related not only to the implementation of a set of functions, but also to the optimization of the choice of solutions in alternative situations. 


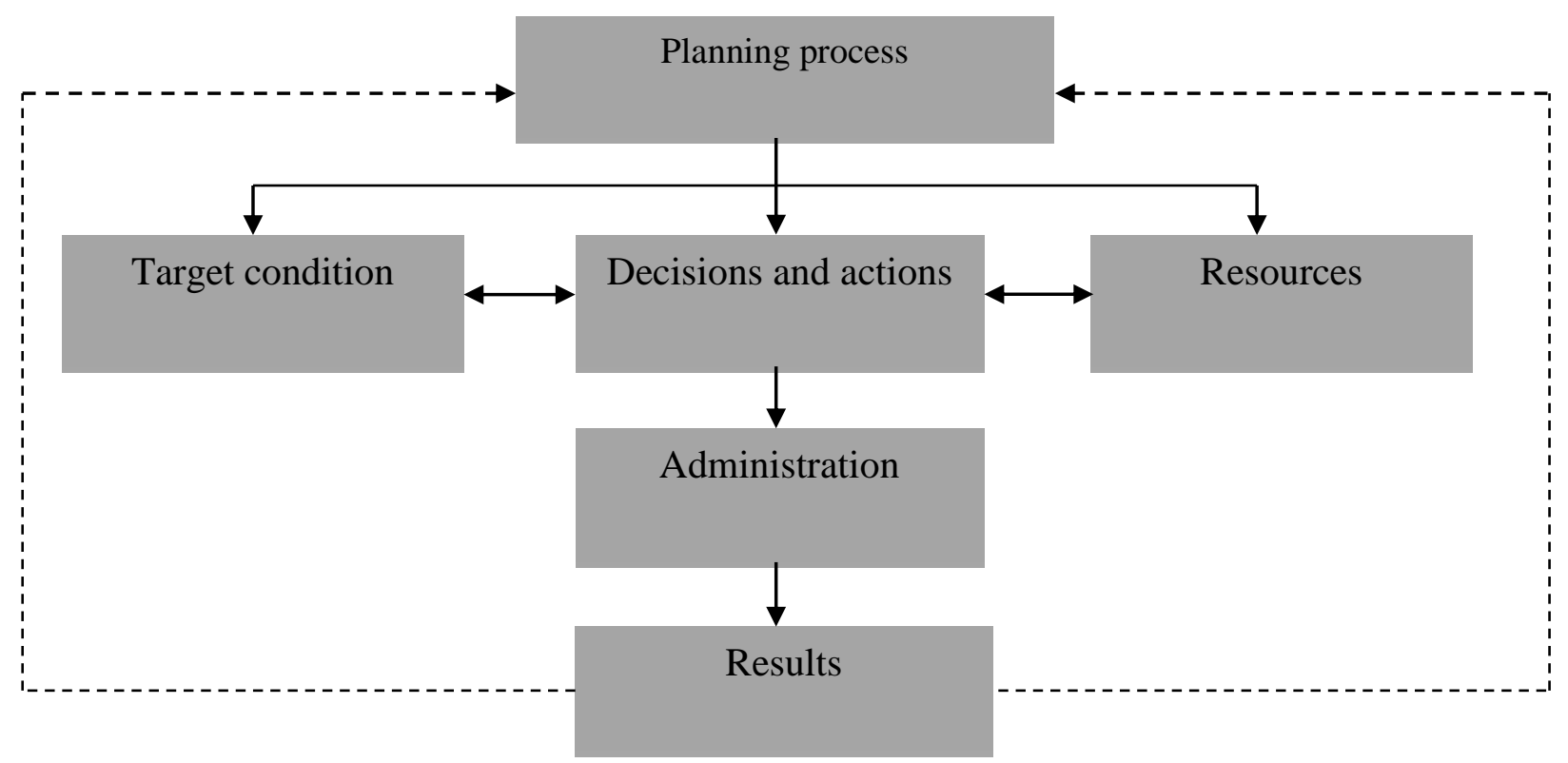

Figure 3. Planning process in the travel company

For the needs of the current dynamic situation, planning should unambiguously determine the actual state of the system of planning activities at the present time.

The comparison of the planned with the actual reporting data is established as a basis for decision making. Only then does information reporting grow into a system of regulation, as the deviations between the plan and the report serve as a basis for finding the causes and, accordingly, for conducting the necessary countermeasures (Man R. Mayer E., 1996). In this way, planning is used, on the one hand, to determine priorities and the timing of goals, and on the other, as a means of resolving conflicts between goals (Jay Galbraith, Robert K. Kazanjian, 1989).

Another essential element of the choice of behavior of the planning system is the definition of activities ensuring the achievement of the target state. Planning should also ensure the obvious need to determine the trajectory of the transition from the actual to the target state, of course with a parallel possibility for flexibility of behavior.

Resources as an element of the choice of behavior of the planning system are a kind of limiters of the series of decisions. The plan should specify the types and amounts of resources required, as well as their potential sources and the distribution of these resources. Specifying resource constraints also includes budgeting.

The strategic orientation towards concept connects the administration of the planning process with the implementation of the following sequence (Mayer E, 1987):

The first stage is related to analyzes and assessments related to the boundaries of activities and decisions in the process of their modeling.

The second stage covers the design and selection of solutions and activities based on planning efforts. Based on the analyzes performed in the first stage, the goals for achievement are formulated and the control norms are determined, and then several options are designed for the ranking of decisions and activities: pessimistic, optimistic and realistic, and subsequent selection of the most the realistic of them.

It is necessary to build a planning infrastructure in business organizations as this can be done for a certain period of time and should be done in stages. This is a prerequisite for the fact that when building a planning system it is necessary to compile an algorithm for construction, providing on 
the one hand rationality, on the other hand, uniformity in the use of employees, as well as continuous business processes in cases where the system of planning is implemented in an active unit. The sequence in the construction of the planning system should be chosen so as to correspond to the technology of the activities performed in the managed system, creating a logical connection in the functioning of the planning system. Such a concept ensures compliance with the degree of different requirements depending on the specific conditions.

The third stage in the process of modeling planning decisions and activities is their implementation. The stage includes implementation through budgeting by main activities. The most rational option is used as a basis for developing and controlling the plan. Often this criterion determines whether the desired target conditions are achieved through the selected solutions and activities, according to the company's budget.

The established planning system, currently in an unprecedented situation created by the growing pandemic, leading to disastrous consequences, especially in the tourism sector, should ensure:

- flexibility - through which it is necessary to ensure functional flexibility related to the possibility of substitutability of one activity with another, as well as numerical flexibility, expressed in the ability to quickly increase or decrease the number of activities that the company will implement and, of course, financial flexibility, which is able to maintain the functional and numerical form of flexibility. On the other hand, a certain degree of stability must be ensured in order to maintain some order and direction of activity; (Dimitrov N. and Tsarev N., 1987)

- comprehensiveness - the established system should provide a sufficiently wide scope of the developed plans, in order to adequately respond to any problematic situation;

- coordination - through planning it is possible to realize and coordinate, on the one hand, the individual planning activities, which are presumably interconnected and on the other hand, the activities of the planning system with the other organizational units;

- clarity - the plans need to be structured in a way that implies clarity and logic. They should specify the target state pursued, determine the appropriate solutions and activities and outline the limits within which certain freedoms of these activities are allowed.

The most significant contribution of modern planning is that it helps the management of travel companies to realize the importance of changes in their management, shifting the focus from product to market and consumer, to begin to change their way of thinking "from the inside out". to "outside-inside".

Flexible planning is above all a method, a way of thinking, so its various functions and tools can be used to increase the effectiveness of management in any area of socio-economic development of society and companies in the tourism sector in particular.

In summary, it can be noted that the planning system involves the organization and complex combination of new reporting to anticipate emerging deviations and signal the need for change. The internal management subsystem of the planning reporting needs to be organized in a way that ensures the existence of a regulatory circle:

- $\quad$ ability to perform planning;

- $\quad$ to compare the plan with the actual, reporting results in constant periods;

- $\quad$ possibility to register and compare the deviations between the plan and the report;

- the ability to make timely decisions to prevent unwanted consequences.

In conclusion, it could be pointed out that decisions and activities need to be based on planning, which sets the planned values that are compared with those actually achieved in certain reporting periods. For this reason, planning is needed, which serves as a basis for the management of the company. The problems of planning have become so diverse that it is necessary to differentiate this activity according to the scale of the business organization. In small and medium- 
sized companies, it is recommended to combine operational plans with budgets. In this case, the budgets do not only represent spending powers, but also help to regulate the set goals, ie. budgeting is actively used as a tool of the adaptive planning system.

\section{Bibliography}

1. Agile Leadership Principles. (2019). Свалено от Taking a Look at the Agile Leadership Model: https://www.quickstart.com/blog/taking-a-look-at-the-agile-leadership-model/

2. Gary Yukl, Richard Lepsinger. (2019). Flexible Leadership. Свалено от Flexible Leadership: https://www.onpointconsultingllc.com/flexible-leadership

3. Jay Galbraith, Robert K. Kazanjian. (1989). Strategi Implementation: Structure, Systems and Process. St.Pau: Minn.: West Publishing.

4. Mayer E. (1987). Controlling Konzepte:Perspektiven fur 90-er jahre. Wiesbaden: WB.

5. Готтхард, П. (2001). (3, Ред.) Проблемы теории и практики управления, 2001, бр.3, стр. 102, 102.

6. Димитров Н. Зафирова Цв. (2001). Стратегическо управление. Варна: УИ.

7. Димитров Н. и Цьрев Н. (1987). Балансови проблеми на планирането на народното стопанство. Варна: УИ.

8. И., С. (2009). Планиране и прогнозиране. София: НБУ.

9. Кабакчиева, Ц. (2019). e-Journal VFU, 1.

10. Ман Р. Майер Е. (1996). Контролинг за начинаещи. Варна: УИ.

11. Министерство на икиномиката. $\left(\begin{array}{llllll}10 & 03 & 2020 & \text { r.). } & \text { Свалено от }\end{array}\right.$ http://www.mi.government.bg/bg

12. Министерство на туризма. (2020). Свалено от Министерство на туризма: https://www.tourism.government.bg/

13. Стоянов В. и др. (1987). Организационно проектиране в стопанските единици. Варна: УИ. 